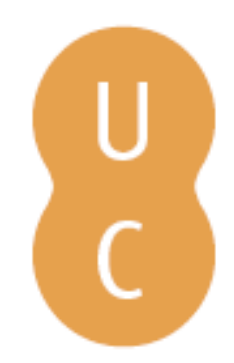

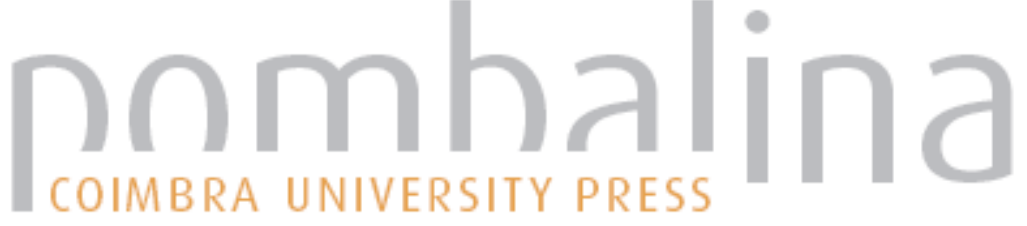

\section{Vida da Faculdade de Letras 2012-2013}

Autor(es): $\quad$ UNIVERSIDADE DE COIMBRA. Faculdade de Letras

Publicado por: Imprensa da Universidade de Coimbra

URL

persistente: URI:http://hdl.handle.net/10316.2/38176

DOI: $\quad$ DOI:http://dx.doi.org/10.14195/978-989-26-1089-4

Accessed : $\quad$ 26-Apr-2023 11:40:35

A navegação consulta e descarregamento dos títulos inseridos nas Bibliotecas Digitais UC Digitalis, UC Pombalina e UC Impactum, pressupõem a aceitação plena e sem reservas dos Termos e Condições de Uso destas Bibliotecas Digitais, disponíveis em https://digitalis.uc.pt/pt-pt/termos.

Conforme exposto nos referidos Termos e Condições de Uso, o descarregamento de títulos de acesso restrito requer uma licença válida de autorização devendo o utilizador aceder ao(s) documento(s) a partir de um endereço de IP da instituição detentora da supramencionada licença.

Ao utilizador é apenas permitido o descarregamento para uso pessoal, pelo que o emprego do(s) título(s) descarregado(s) para outro fim, designadamente comercial, carece de autorização do respetivo autor ou editor da obra.

Na medida em que todas as obras da UC Digitalis se encontram protegidas pelo Código do Direito de Autor e Direitos Conexos e demais legislação aplicável, toda a cópia, parcial ou total, deste documento, nos casos em que é legalmente admitida, deverá conter ou fazer-se acompanhar por este aviso. 


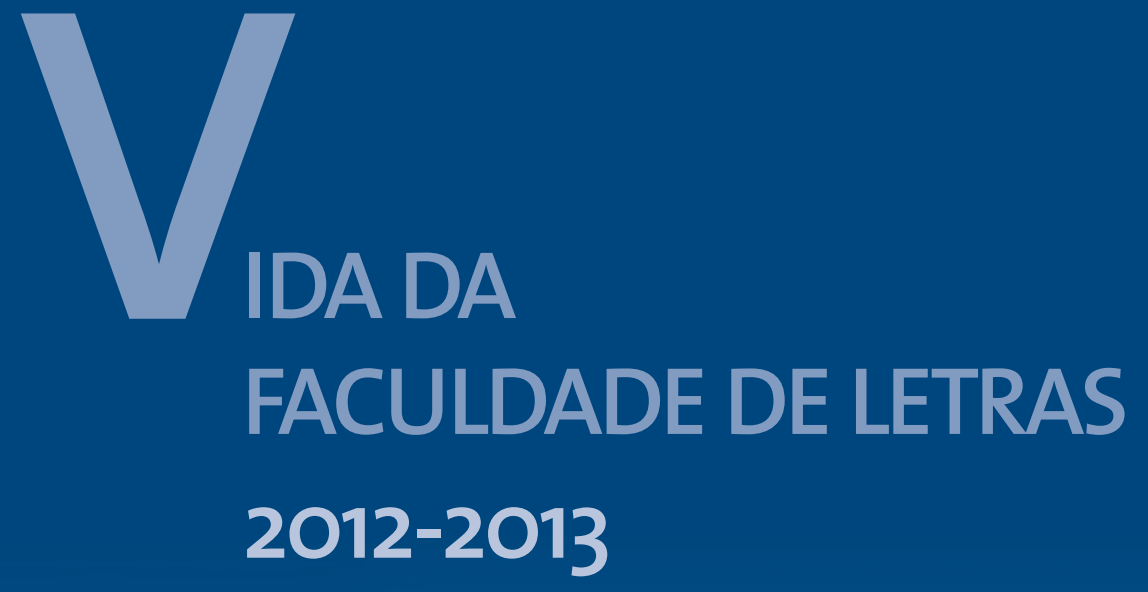

Faculdade de Letras da Universidade de Coimbra 
(Página deixada propositadamente em branco) 
$\because 1+1+1+1+1$

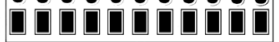

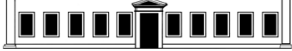

D

0

C

U

M

E

N

T

0

S

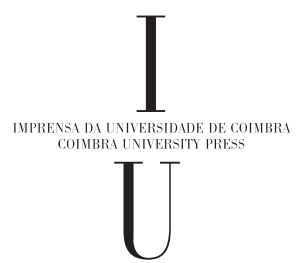


EDIÇÃo

Imprensa da Universidade de Coimbra Email: imprensa@uc.pt

URL: http//www.uc.pt/imprensa_uc

Vendas online: http://livrariadaimprensa.uc.pt

COORDENAÇÃO EDITORIAL

Imprensa da Universidade de Coimbra

CONCEÇÃo GRÁFICA

António Barros

IMAGEM DA CAPA

Foto: António Barros, 2005.

INFOGRAFIA

Mickael Silva

ISBN DIGITAL

978-989-26-1089-4

DOI

http://dx.doi.org/10.14195/978-989-26-1089-4 


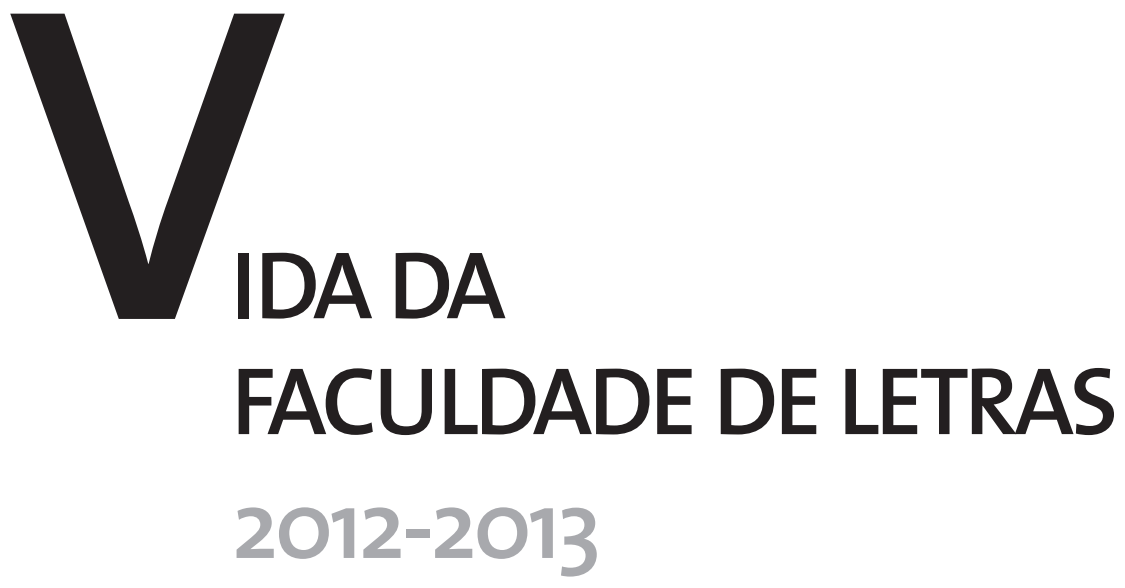

Faculdade de Letras da

Universidade de Coimbra 
(Página deixada propositadamente em branco) 


\section{S U M Á R I O}

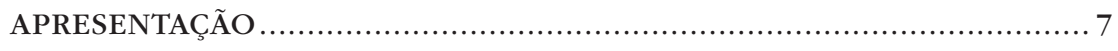

IN MEMORIAM .................................................................. 9

OBITUÁRIO........................................................................... 13

PROVAS DE AGREGAÇÃO E DOUTORAMENTOS .............................. 17

ATIVIDADE CIENTÍFICA DOS DEPARTAMENTOS ......................... 23

Congressos, Colóquios, Conferências e Encontros Científicos ......... 25

Eventos de Natureza Pedagógica ........................................ 39

PUBLICAÇÕES ................................................................. 43 
(Página deixada propositadamente em branco) 


\section{A P R E S E NT A Ç Ã O}

A partir do ano letivo de 2012/2013, toda a informação que integrava a secção "Vida da Faculdade", da Revista Biblos passa a ter uma existência autónoma em formato digital.

Por se considerar relevante preservar essa memória e por se entender que ela não deve integrar uma revista científica, cria-se esta publicação à parte, acessível ao público interno e externo, que passa a estar alojada na página web da Faculdade de Letras e nas plataformas da Imprensa da Universidade.

Neste volume, reunem-se informações relativas ao ano letivo de $2012 / 2013$. 
(Página deixada propositadamente em branco) 


\section{IN MEMORIA M}

Maria Francisca Mendes Queiroz Pinto de Athayde $(3 / 10 / 2013)$

A Secção de Estudos Germanísticos da Faculdade de Letras da Universidade de Coimbra perdeu, a 3 de outubro de 2013, uma das suas professoras mais ativas e dedicadas.

A sua ausência representa um empobrecimento particularmente difícil de superar. Maria Francisca Mendes Queiroz Pinto de Athayde serviu a FLUC ao longo de mais de 30 anos de docência, atividade a que se dedicou com toda a energia que lhe conhecemos e que não deixou indiferente nenhum dos numerosos estudantes que lhe passaram pelas mãos. Preparava minuciosamente as suas aulas e era detentora de uma extraordinária capacidade de adaptar os conteúdos ao nível dos seus estudantes, sem nunca comprometer o rigor científico. A vivacidade, o bom humor e a clareza sempre presentes na sua lecionação eram secundados por uma atenção especial a cada um/a dos/das alunos/as. $\mathrm{O}$ cuidado que punha na relação pedagógica esteve sempre presente - mesmo na situação de doença, manteve contacto com mais de 300 ex-alunos/as, através de um grupo fechado, na rede social Facebook. Encontrou ali uma forma de desenvolver a relação com ex-estudantes, que se traduziu em inúmeras situações de partilha de informação de teor muito diversificado, compreendida entre os temas linguísticos e as ofertas de emprego para profissionais de língua estrangeira. 
O contributo que deu à FLUC não se confinou à atividade docente, que esteve sempre associada a uma profícua atividade de investigadora e ainda à participação empenhada na vida da Faculdade, como testemunham a sua pertença ao CIEG, a produção bibliográfica extensa e os registos da sua passagem por inúmeras comissões, grupos de trabalho e órgãos de gestão, bem assim o contributo precioso para a construção do Centro de Línguas da FLUC. Foi durante o seu mandato de Diretora (2008-10) e graças à sua energia que o CL se assumiu como projeto credível de um serviço de qualidade prestado pela FLUC à comunidade intrauniversitária e extrauniversitária.

As etapas fundamentais do seu percurso académico podem descrever-se de forma sucinta. Francisca Athayde licenciou-se, em 1981, em Línguas e Literaturas Modernas (variante de Estudos Ingleses e Alemães), tendo sido contratada como Assistente Estagiária do Grupo de Estudos Germanísticos, em 1982. No ano de 1987, prestou Provas de Aptidão Pedagógica e Capacidade Científica e transitou para a categoria de Assistente. Com uma dissertação concluída em 2000 e intitulada A estrutura semântica das construções com verbo-suporte preposicionadas do Português e do Alemão, obteve o grau de Doutora em Letras pela UC, na Especialidade de Linguística Contrastiva (Português-Alemão) e foi contratada como Professora Auxiliar da FLUC. Em 2008, obteve provimento como Professora Associada, tendo-se apresentado a concurso com o relatório Programa, Conteúdos e Métodos de Ensino Teórico e Prático das Matérias da Disciplina de "Seminário de Linguística" do $4^{\circ}$ grupo (Estudos Germanísticos), FLUC: 2007.

No seu longo percurso docente, lecionou diversas disciplinas nos cursos de licenciatura, nomeadamente Introdução aos Estudos Linguísticos, Linguística Alemã 1 e 2 e ainda Seminário de Linguística Alemã I e II, tendo igualmente assegurado um seminário do Curso de Mestrado e Pós-Graduação em Estudos Germanísticos (Área de Especialização em Estudos Luso-Alemães) e o Seminário de Léxico 
no Mestrado em Linguística e Ensino. Coorientou várias dissertações de mestrado e doutoramento. Também no âmbito do Ramo de Formação Educacional, Francisca Athayde prestou valiosos serviços à FLUC, quer na qualidade de supervisora/orientadora de professores/as estagiários/as de Alemão quer como Presidente da Área de Formação de Estudos Germanísticos, cargo que desempenhou entre 2001 e 2007.

A participação ativa na vida da FLUC e da Secção comporta ainda, para além da Direção do Centro de Línguas e da Presidência da Área de Formação de Estudos Germanísticos acima mencionadas, a pertença à Comissão Coordenadora do Conselho Científico e a Representação deste órgão na Comissão de Supervisão do Ramo Educacional, bem como um mandato na Comissão Científica do DLLC e na Assembleia de Faculdade. O elenco exaustivo do grande número de grupos de trabalho e comissões de reestruturação e acompanhamento de reformas curriculares em que participou tornaria fastidiosa a leitura deste texto. No entanto, seria injusto não dar relevo ao seu papel de "embaixadora" da FLUC e da língua alemã junto das comunidades escolares, em diversas ações de sensibilização para os cursos com a componente de Alemão. Merecem igualmente destaque os contactos que manteve com universidades e investigadores alemães, no âmbito do programa Erasmus. A sua condição de germanista levou-a ainda a integrar a Associação Portuguesa de Estudos Germanísticos, desde a primeira hora, e a assumir um mandato como membro da Direção da mesma associação.

$\mathrm{Na}$ qualidade de investigadora, Francisca Athayde afirmou-se como especialista de referência em Fraseologia Contrastiva, sendo autora de dois números da série Cadernos do CIEG e de dezenas de artigos científicos, com especial ênfase no par de línguas Português e Alemão, embora não estejam ausentes da sua produção as referências ao fraseoléxico de outras línguas indo-europeias e não 
indo-europeias. Não obstante, a sua investigação versou também sobre temas de tradução, no âmbito de um projeto sediado no CIEG, tendo conduzido à publicação (em colaboração) de vários artigos sobre os problemas associados à tradução de nomes compostos, adjetivos e verbos modais do Alemão.

$\mathrm{O}$ retrato que procurei esboçar, para memória futura da Professora Maria Francisca Athayde, representa apenas de forma mitigada o seu perfil de profissional. O muito que haveria a dizer sobre o ser humano de quem fui aluna, colega e amiga não se compagina com os limites impostos a um texto deste teor.

Ficam em todos nós a memória viva da convivência pessoal e profissional, com todos os matizes que lhe conhecemos, e a perplexidade que retomo nas palavras de uma ex-aluna: "É difícil conceber como é possível que a morte chegue prematuramente a quem é a própria personificação da vida..."

Rute Isabel Fernandes Soares

(Professora Auxiliar da FLUC) 


\section{O B I T U Á R I O}

\section{Doutor José Manuel Cardoso Alves da Mota}

1948-2013

Tive o gosto de escrever, nesta mesma revista, sobre o percurso académico do Doutor José Manuel Mota enquanto docente e investigador da Secção de Estudos Anglo-Americanos da Faculdade de Letras da Universidade de Coimbra, quando da sua aposentação prematura por razões de saúde em 2007. Sobre a nossa relação, entre orientadora-aprendiza e orientando-mestre, deixei então testemunho (Biblos, vol.V, $2^{\text {a }}$ série, 2007, pp.539-542). Aprendi nesse processo mais ainda do que aquilo que o Doutor José Manuel Mota, profissional de primeira água e cidadão íntegro e atento ao mundo, sempre teve para nos ensinar. Em agosto passado, o sofrimento motivado por uma saúde precária, de que ele sempre se recusou estoicamente a tirar partido mas que acabou por forçar a sua precoce retirada da academia naquele ano, acabou de vez.

Foi um grande privilégio ter conhecido de perto José Manuel Mota e ter merecido a sua amizade. Uma das pessoas mais cultas que conheci no mundo académico que tem sido o meu desde há cinquenta anos dos dois lados do Atlântico (e não estou a esquecer o grande Paulo Quintela, mestre de nós dois), José Manuel Mota alimentava a sua excecional inteligência de uma curiosidade intelectual sempre insaciável, quer no respeitante à docência e 
investigação, quer no respeitante à complexa realidade do mundo em que vivemos. Apaixonado pelas artes da língua, José Manuel Mota possuía também nas suas estantes inúmeras obras, que tinha o hábito de ler com cuidado, sobre as ciências ditas exatas - física, física teórica, física quântica, biologia, cibernética. Doutorou-se em 1995 com uma tese sobre o autor americano de ficção científica, Philip K. Dick, intitulada O efeito de irreal. A fantasia científica de Philip K. Dick. Esse excelente trabalho ficou por publicar, devido aos obscuros critérios de "interesse nacional" que presidiam então aos programas de publicação de teses académicas em Portugal. $\mathrm{O}$ andróide não tinha mistérios para este autor. E muito menos o ciborgue. Vítima de malformação cardíaca congénita, e salva a sua vida por bypasses em mais do que uma cirurgia, José Manuel Mota sobreviveu literalmente no pós-humano (como tantos de nós hoje em dia, sem disso nos darmos conta).

Também o mistério da língua o fascinava, não só como competente linguista que era, mas de igual modo como leitor apaixonado de poesia (no sentido lato do termo). Irão os poetas sempre à frente, como dizia Rimbaud? Seremos nós que falamos a língua, ou é ela que nos fala? Dizem as diferentes línguas a mesma coisa, ou coisas diferentes? Será a língua na cultura ocidental intrinsicamente sexista? Sobre este último ponto refletiu José Manuel Mota num breve prefácio que escreveu para um ensaio marcante sobre educação e sexismo na linguagem, da autoria de Graça Abranches e Eduarda Carvalho, intitulado Linguagem, poder, educação. O sexo dos B,A,Bas (Lisboa: Comissão para a Igualdade e para os Direitos das Mulheres, 1999). Que "uma linguagem diferente significa de facto um mundo diferente", conclui José Manuel Mota, "só nas Utopias, de Swift a LeGuin (ou Haden-Elgin)".

Para lidar com o potencial e as limitações das línguas, nada como aprender o maior número possível delas. Além de línguas 
românicas e germânicas, que eram razoavelmente familiares a quem, como ele, ou eu, ingressava nos meados do século passado num curso de Filologia Germânica, José Manuel Mota fez questão de estudar árabe e russo, e exibia, sempre que necessário, com propriedade e segurança, o latim correto que continuava a cultivar. O seu percurso académico pautou-se por um grande rigor filológico e científico, e por uma atualização constante, fosse no âmbito da linguística ou da literatura, da ficção científica ou dos estudos americanos e culturais. O pensamento utópico, designadamente em H. G. Wells, o autor inglês considerado um dos inventores da literatura de ficção científica, suscitou-lhe algumas das reflexões mais interessantes. Membro da Wells Society, José Manuel Mota deixou-nos como último trabalho publicado justamente uma criteriosa recensão de uma obra sobre H. G. Wells, da autoria do espanhol Alberto Lázaro, intitulada H. G. Wells en España. Estudio de los expedientes de censura (1939-1978) (Madrid: Editorial Verbum, 2004). A recensão apareceu em The Wellsian. The Journal of H. G. Wells Society, $\mathrm{n}^{\circ} .30$ (2007) 64-66. Como José Manuel Mota explica logo no início, o livro de Lázaro é um desenvolvimento do artigo publicado em The Reception of H. G. Wells in Europe, organizado por Patrick Parrinder e John S. Partington (London: Thoemmes Continuum, 2005). Para este volume contribuiu também José Manuel Mota com um belo ensaio sobre Wells em Portugal, intitulado "News from Nowhere. Portuguese Dialogues with H. G. Wells". Entre nós, ficou lamentavelmente por publicar a conferência com que José Manuel Mota se despediu dos seus colegas da Faculdade de Letras imediatamente antes da aposentação. "Wells e Portugal. Encontros e desencontros" é, com ligeiras alterações de adequação ao contexto da apresentação, uma versão em língua portuguesa desse ensaio sobre a receção de Wells em Portugal. Que melhor homenagem do que trazer agora a lume em português este perspicaz e bem informado texto? 
Em agosto de 2013, a morte interrompeu a vida de um académico português de reputação internacional. Mais do que isso, a morte levou-me um grande amigo. Mas não calou de vez o espírito crítico e inquieto que ecoa ainda nos vários ensaios sobre ficção científica que o Doutor José Manuel Mota nos deixou.

Coimbra, 11 de março de 2014

Maria Irene Ramalho de Sousa Santos (Professora Catedrática da FLUC) 
PROVAS DE AGREGAÇÃO E DOUTORAMENTOS

\section{Agregação}

Em 2013 prestaram provas de agregação os seguintes professores: 10/01/13: Doutora Carmen Isabel Leal Soares, Estudos Clássicos - Mundo Antigo.

18/02/2013: Doutor Diogo Falcão Ferrer, Filosofia.

\section{Doutoramento}

No ano letivo de 2012/2013, realizaram-se os seguintes doutoramentos em Letras:

Marco Daniel Carrola Duarte, na área de História, especialidade História da Arte, com o tema, "Fátima e a criação artística (1917-2007): o Santuário e a Iconografia - a arte como cenário e como protagonista de uma específica mensagem." (4 volumes), orientado pela Doutora Maria Regina Dias Baptista Teixeira Anacleto, no dia 02/01/2013, tendo sido Aprovado com distinção e louvor por unanimidade.

Aurélio Paulo da Costa Henriques Barradas, na área de História, especialidade História da Idade Média, com o tema, Martyrologivm Lamecense (Texto e Comentário), orientado pelo Doutor Saul 
António Gomes Coelho da Silva e pelo Doutor António Manuel Ribeiro Rebelo, 23/03/2013, tendo sido Aprovado com distinção e louvor por unanimidade.

Anselmo Alves Neetzow, na área de História, especialidade História dos Descobrimentos e da Expansão Portuguesa, com o tema A Construção Colonial da Província Platina nos Séculos XVI a XVII, orientado pelo Doutor José Manuel Azevedo e Silva, 30/04/2013, tendo sido Aprovado por maioria.

Cornelia Elisabeth Plag (FLUC), especialidade Estudos de Tradução, com o tema Vocabulário jurídico para tradutores de Português-Alemão, orientada pela Doutora Maria Rute Vilhena Costa (FCSH da Universidade Nova de Lisboa) e pela Doutora Maria Francisca Mendes Queiroz-Pinto de Athayde, 08/04/2013, tendo sido Aprovada com distinção e louvor por unanimidade.

Ana Isabel Sacramento Sampaio Ribeiro (FLUC), na área de História, especialidade História Moderna, com o tema Nobrezas e Governança. Identidades e Perfis Sociais (Coimbra 1777-1820). orientada pela Doutora Maria Margarida Sobral da Silva Neto e pelo Doutor Joaquim Ramos de Carvalho, 27/09/2013, tendo sido Aprovada com distinção e louvor por unanimidade.

Hermínia Maria Pimenta Ferreira Sol, na área de Línguas e Literaturas Modernas, especialidade Literatura Americana, com o tema The impossible fusion of horizons: a temática das viagens na contística de Paul Bowles, orientada pela Doutora Graça Maria Constantino Nunes de Oliveira Capinha e pela Doutora Jacinta Maria Cunha da Rosa Matos, 03/01/20013, tendo sido Aprovada com distinção e louvor por unanimidade. 
Mónica Belchior Morais de Brito, $3^{\circ}$ Ciclo, Turismo, Lazer e Cultura, ramo Turismo e Desenvolvimento, com o tema Percursos de sustentabilidade: politicas e práticas de planeamento para o desenvolvimento turístico no Município de Sines, orientada pela Doutora Fernanda Maria da Silva Dias Delgado Cravidão, 08/02/2013, tendo sido Aprovada com distinção e louvor por unanimidade.

Maria de Fátima Marques Loureiro Morgado, especialidade Estudos Anglo-Americanos, Filosofia e Sociologia, com o tema Escritas de sombra. Auto-retrato e outras ruínas. Entre Derrida e Joyce, orientada pela Doutora Maria Fernanda Bernardo Alves e pela Doutora Isabel Maria Correia Pedro dos Santos, 04/02/2013, tendo sido Aprovada com distinção e louvor por unanimidade.

Ana Maria Mendes Ruas Alves, na área de História, especialidade História Moderna, com o tema O Reyno de Deos e a Sua Justiça. Dom Frei Inácio de Santa Teresa (1682-1751), orientada pelo Doutor José Pedro de Matos Paiva, 27/03/2013, tendo sido Aprovada com distinção e louvor por unanimidade.

Reina Marisol Troca Pereira, na área de Estudos Clássicos, especialidade Literatura Grega, com o tema Agamemnon(es): entre o mito e a literatura, orientada pela Doutora Maria de Fátima Sousa e Silva, 28/03/2013, tendo sido Aprovada com distinção e louvor por unanimidade.

Fausto Cruchinho Dias Pereira, $3^{\circ}$ Ciclo, Estudos Artísticos, ramo Estudos Fílmicos e da Imagem, com o tema Roberto Rossellini: A "Televisão de Autor", orientado pelo Doutor António Pedro Couto Rocha Pita, 03/04/2013, tendo sido Aprovado com distinção e louvor por unanimidade. 
Ana Isabel Correia Martins, na área de Estudos Clássicos, especialidade Literatura Neolatina, com o tema Pedagogia, Retórica Escolar e Génese do Discurso Literário no Renascimento: Uma Leitura da Collectanea Moralis Philosophiae de Frei Luís de Granada, orientada pela Doutora Nair de Nazaré de Castro Soares, 09/04/2013, tendo sido Aprovada com distinção e louvor por unanimidade.

Luíra Freire Monteiro, $3^{\circ}$ Ciclo, Identidades Práticas e Representações no Mundo Contemporâneo, com o tema Retórica da alteridade: Portugal e os portugueses na historiografia brasileira, orientada pelo Doutor António Martins da Silva e pelo Doutor Iranilson Buriti de Oliveira, 24/04/2013, tendo sido Aprovada com distinção e louvor por unanimidade.

Carla Sofia da Silva Ferreira, $3^{\circ}$ Ciclo, Língua Portuguesa: Investigação e Ensino, com o tema Usos do particípio passado duplo no Português Europeu Contemporâneo: Padrões de Variação numa Amostra de População Escolar orientada pela Doutora Cristina dos Santos Pereira Martins e pela Doutora Isabel Maria de Almeida Santos, 29/04/2013, tendo sido Aprovada com distinção e louvor por unanimidade.

Marisa das Neves Henriques, na área de Filosofia, especialidade Filosofia e Cultura Portuguesas, como tema A caminho de uma espiritualidade laica: Ciência, Filosofia e Teologia no Orto do Esposo (tensões histórico-filosóficas e semânticas), orientada pelo Doutor Mário Avelino Santiago de Carvalho, 07/05/2013, tendo sido Aprovada com distinção e louvor por unanimidade.

Marta Alice Gabriel Soares, $3^{\circ}$ Ciclo, Estudos Americanos, com o tema "I know it hurts to burn". Joan of Arc as an incendiary metaphor in Adrienne Rich's poetry and prose, orientada pela Doutora 
Maria Irene de Abreu Ramalho de Sousa Santos, 08/05/2013, tendo sido Aprovada com distinção e louvor por unanimidade.

Maria do Rosário Neto Santos Mariano (FLUC), na área de Línguas e Literaturas Modernas, especialidade Literatura Francesa, com o tema, Sentidos do Trágico. O Trágico Sério e suas Figurações no Teatro de Jean Anouilh, orientada pela Doutora Ofélia Milheiro Caldas Paiva Monteiro e pelo Doutor Michel Lioure (Univ. Blaise Bascal), no dia 23/5/2013, tendo sido Aprovada.

Éllida Neiva Guedes, na área de Ciências da Comunicação, especialidade Media e Sociedade, com o tema A Mediação dos Relacionamentos Institucionais nas Práticas de Inclusão Social da Universidade Federal do Maranhão - A Universidade Federal do Maranhão no Espaço Público: as fronteiras simbólicas como lugar de mediação, orientada pela Doutora Isabel Maria Ribeiro Ferin Cunha e pela Doutora Margarida M. Krohling Kunsch (Universidade de São Paulo), 24/05/2013, tendo sido Aprovada com distinção e louvor por unanimidade.

Ana Isabel Simões Dias Vieira Barbosa, na área de Línguas e Literaturas Modernas, especialidade Linguística Portuguesa, com o tema Derivação Nominal em Português. Denominações em -ISMO, orientada pela Doutora Graça Maria de Oliveira e Silva Rio-Torto, 11/06/2013, tendo sido Aprovada com distinção e louvor por unanimidade.

Stefano Salmi, na área de História, especialidade História Contemporânea, com o tema Le relazioni fra l'Italia e il Portogallo durante il periodo fascista e l'Estado Novo orientado pelo Doutor Luís Manuel Soares dos Reis Torgal e pelo Doutor Alberto De Bernardi (Univ. Bolonha), 25/06/2013, tendo sido Aprovado por maioria. 
Priscilla Gontijo Leite, $3^{\circ}$ Ciclo, Estudos Clássicos - Mundo Antigo, com o tema Ética e retórica forense: asebeia e hybris na caracterização dos adversários em Demóstenes, orientada pelo Doutor Delfim Ferreira Leão, 15/07/2013, tendo sido Aprovada com distinção e louvor por unanimidade.

Marinete Luzia Francisca de Souza, $3^{\circ}$ Ciclo, Literatura Portuguesa, ramo (Investigação e Ensino), com o tema A Literatura Amazônica: dos textos de viagem aos romances contemporâneos, orientada pela Doutora Maria Aparecida Ribeiro, 22/07/2013, tendo sido Aprovada com distinção e louvor por unanimidade. 
ATIVIDADE CIENTÍLICA DOS DEPARTAMENTOS 
(Página deixada propositadamente em branco) 


\section{CONGRESSOS, COLÓQUIOS,C ONFER ÊNCIASE ENCONTROSCIENTÍTICOS}

\section{Departamento de Filosofia, Comunicação e Informação}

26 SETEMBRO 2012 | Conferência por Genaro Luís Garcia Lopez (Universidade de Salamanca):

"Aspectos éticos de la información”.

27 SETEMBRO 2012 | Palestra por Rita Basílio de Simões:

"Exorcizando demónios: media e justiça criminal", no âmbito do Ciclo de debates e tertúlias Comunicação e Jornalismo em debate (FLUC/CEIS20).

1 OUTUBRO 2012 | Conferência Marcelo Rebelo de Sousa

"A Comunicação Social em Mudança: Portugal 2012", no âmbito da sessão de abertura da Licenciatura em Jornalismo e do Mestrado em Comunicação e Jornalismo.

8 OUTUBRO 2012 | Conferência por Reynner Franco (Universidade de Salamanca):

"La singularidade del concepto. Sobre la pretensión de objetividad del conocer según Hegel y McDowell”.

19 OUTUBRO 2012 | Conferência por Fabrízio Macagno

(Universidade Nova de Lisboa):

«Persuasive definitions and motive language». 
19 OUTUBRO 2012 | Conferência por Cláudio Reichert do Nascimento

(Universidade Federal de Santa Catarina):

"Identidade e corporeidade: mudanças conceituais na obra de Paul Ricoeur", uma iniciativa do projeto de investigação LIF "A racionalidade entre afetividade e norma».

25 OUTUBRO 2012 | Palestra por Carlos Reis

"Contando histórias, fazendo personagens", no âmbito do Ciclo de debates e tertúlias Comunicação e Jornalismo em debate: (FLUC/ CLP/CEIS20).

8 NOVEMBRO 2012 | Conferência por Jorge Lozano

(Grupo de Estudios de Semiotica de la Cultura - Universidad Complutense de Madrid):

«La moda como metrónomo cultural».

8 NOVEMBRO 2012 | Conferência José Luis Bonal Zazo

(Universidade da Extremadura):

"A investigação em Arquivística sob a mudança de paradigma".

8 NOVEMBRO 2012 | Palestras Ciência da Informação

Jose Luis Bonal Zazo e Pilar Ortega (Universidade da Extremadura): "Os estudos de informação e documentação na universidade da Extremadura" e "Cooperação inter-universitária em docência e investigação".

9 NOVEMBRO 2012 | Conferência por Maria Albergamo

(Grupo de Estudios de Semiotica de la Cultura, da Universidade Complutense de Madrid):

"Museo y narraciones de moda". 
9 NOVEMBRO 2012 | Conferência por Jorge Lozano

(Grupo de Estudios de Semiotica de la Cultura, da Universidade Complutense de Madrid):

"Wikileaks: un archivo de opacidades y transparência".

15 NOVEMBRO 2012 | Palestra por Clara Almeida Santos

"Televisões WEB universitárias", no âmbito do Ciclo de debates e tertúlias Comunicação e Jornalismo em debate (FLUC/CEIS20).

19 A 23 NOVEMBRO 2012 | Seminário por Luis Pablo Francescutti

(Facultad de Ciencias de la Comunicación de la Universidad Rey Juan Carlos):

"La Cara Oscura de la Communicación: secretos y filtraciones en la sociedad de la información".

28 NOVEMBRO 2012 | Colóquio Intercâmbio Cultural: Diálogos Brasil-Portugal

5, 6 DEZEMBRO 2012 | Seminário

"Jornalismo e Comunicação - O valor da comunicação e a(s) marca(s) da informação".

10 DEZEMBRo 2012 | Colóquio

"Serviço Público de Rádio e Televisão - Porquê? Que Futuro?"

(Iniciativa organizada em parceria pelos Cursos de Jornalismo da Faculdade de Letras da Universidade de Coimbra e de Comunicação Social da Escola Superior de Educação de Coimbra).

13 DEZEMBRO 2012 | Palestra por João Figueira

"A Comunicação como valor acrescentado: as cidades como marca e a marca das cidades", no âmbito do ciclo de debates e tertúlias Comunicação e Jornalismo em debate (FLUC / CEIS20). 
18 FEVEREIRO 2013 | Colóquio (FLUC/CEIS20)

"Literacia dos Media. Novos desafios para a educação e para a comunicação".

25, 26 FEVEREIRO 2013 | II Jornadas de Comunicação e Desporto O Herói desportivo.

(CEIS20/FLUC)

21 MARÇO 2013 | Conferência por Soraya Nour

(Investigadora da FCT, da Universidade Portucalense e Universidade Autónoma):

"Estética e Natureza em Alexander von Humboldt".

21, 22 MARÇO 2013 | Colóquio de Pós-Graduação em Filosofia

6 ABRIL 2013 | Workshop

"Aspectos do desenvolvimento do modelo causal»

(Org. pelo Grupo "Sistemas Filosóficos” da Unidade I\&D LIF).

12 ABRIL 2013 | Conferência por Bruno Leclercq

"Logiques Meinongiennes Versus Logiques Frégéo-Russelliennes"

(No âmbito do LIF).

30 ABRIL 2013 | Conferência por Jon Zabala Vazquez

(Universidade Complutense de Madrid):

"La bibliografia material y los estúdios literários".

3 e 4 MAIO 2013 | International Colloquium

"The role of analogy in argumentation discourse».

30 MAIO 2013 | Conferência por Henrique Jales Ribeiro

"Filosofia e ciência na segunda metade do século XIX". 


\section{Departamento de Geografia}

25 SETEMBRO 2012 | Colóquio de Abertura do Novo Ano Letivo 2012/13

"Geografia e Conhecimento do Mundo:

Viagens e Investigação Aplicada”.

Conferencistas:

Fernando Rebelo: "Viagens de lazer, uma rara possibilidade de investigação geográfica”.

Fernanda Cravidão: "Viagens, territórios e culturas: olhares (que não são) neutros”.

Lúcio Cunha: "Viagens e Geografia: leituras geográficas em ambientes frios".

Apresentação de trabalhos de investigação desenvolvidos pelos seguintes estudantes de Mestrado e Doutoramento:

Andreia Martins, Sofia Bernardino, Sofia Fernandes, Luiz Rodolfo Alves, Ana Lapinha Lourenço, Carolina Davide Alves, Carlos Manuel Querido, Marília Dulce Maurício, André Roque e Catarina Nabais.

Entrega de Prémios Curriculares de Geografia aos melhores alunos dos anos letivos de 2009/10, 2010/11 e 2011/12:

Ano letivo de 2011/12:

Carla Patrícia Pedroso Mateus e Carolina Davide Alves Ano letivo de 2010/11:

Sofia Pires Fernandes e Luiz Rodolfo Simões Alves 


\section{Ano letivo de 2009/10:}

Sandra Maria Saraiva dos Santos e Daniel Filipe Esteves Gonçalves

23 OUTUBRO 2012 | Aula Aberta por Messias Modesto dos Passos (UNESP, Campus de Presidente Prudente)

"Os domínios da Natureza no Brasil".

(No âmbito da disciplina de Morfodinâmicas Atuais, do Mestrado em Geografia Física)

7 MARÇO 2013 | Seminário Internacional

"O pensamento de Milton Santos e a Geografia Brasileira".

(Organizado pelo Grupo 3 do CEGOT - Centro de Estudos de Geografia e Ordenamento do Território, coordenado pelos Doutores Norberto Santos e Edna Furtado)

\section{MARÇO 2013 | MASTER CLASS}

"A voz como instrumento de trabalho: técnicas e cuidados vocais".

Jacinta (Doutoranda em Jazz Vocal /Mestre em Jazz Vocal pela Manhatten School of Music, Licenciada em Composição Clássica: Artista Blue Note Records, Organização do Conselho de Formação de Professores e Departamento de Geografia da Faculdade de Letras da Universidade de Coimbra.

\section{Departamento de História, Estudos Europeus, Arqueologia e Artes}

11 OUTUBRO 2012 | Percursos e Discursos. O $3^{\circ}$ Ciclo em Arqueologia na FLUC

Participantes:

Carlo Emanuele Bottaini, Depósitos metálicos no Centro e Norte de Portugal. Balanço da investigação do nosso projeto de doutoramento. 
Ana Bica Dias Osório, Cerâmicas do avesso: cortes físicos e cozeduras concetuais revisitam alguns temas do Bronze Final.

Dulcineia Pinto, Método estatístico aplicado ao conjunto cerâmico do Crasto de Palheiros - Sua explicação.

André Gonçalo Moreira Tomé, Os caminhos da cidade: uma análise da circulação e controlo do espaço urbano em cidades mesopotâmicas do terceiro milénio.

Vera Lúcia Cavaco Pereira, Zooarqueologia Calcolitica e da Idade do Ferro de Além Tejo.

Ricardo Daniel Figueiredo Cabral, Anatomia de uma comunidade rural: o período Helenístico em Tell Beydar.

Ana Paula Ramos Ferreira, Património Cultural e Cidadania.

Ricardo Costeira da Silva, Diacronias e sincronias da investigação arqueológica no Museu Nacional de Machado de Castro.

Maria Pilar M. Reis, Desconstruindo hypocausta: como as termas romanas podem afetar o nosso código filosófico.

15 NOVEMBRO 2012 | $7^{\circ}$ Encontro com Artistas Contemporâneos: Pedro Croft, no Museu da Ciência da UC.

7 DEZEMBRO 2012 | Colóquio Jean-Jacques Rousseau em debate: Sociedade, política e estado. Trezentos anos depois.

Participantes:

Marta Teixeira Anacleto, "Utopia e bucolismo em Rousseau. Autobiografia e ficção".

Custódia Alexandra Almeida Martins, "Pensar a condição humana em Jean-Jacques Rousseau".

Maria Fernanda da Silva Henriques, "Rousseau e Poulain de La Barre - dois caminhos possíveis para a cidadania das mulheres". 
Ana Cristina Araújo, "Leituras do Contrato Social. A influência de J.-J. Rousseau nos inícios do século XIX em Portugal”.

Diogo Pires Aurélio, "O que significa "examinar o ato pelo qual um povo é um povo".

Fernando Augusto Machado, "Percursos de Rousseau em Portugal: variações em torno da soberania do povo”.

Alexandre Franco de Sá, "Rousseau e a questão da representação". Fernando Catroga, "O "contrato sentimental" no Contrato Social de Rousseau".

Ofélia Paiva Monteiro, "Ecos de Rousseau em Garrett: recuperável no tempo histórico, a inocência feliz da idade do ouro?”.

7 DEZEMBRO 2012 | Conferência de Carla Coimbra Alves,

"Marketing cultural e divulgação nos Museus"

14-15 DEZEMBRO 2012 | Jornadas da Pós-Graduação em Estudos Artísticos

Estudos Musicais Mundos e Fundos. Mundos museológico e interpretativo dos fundos musicais, no Instituto Justiça e Paz/Mosteiro de Santa Cruz/Capela da Universidade.

20-21 FEVEREIRO 2013 | Congresso Narrativas da paisagem. O olhar da Geografia, do Cinema e da Literatura, no Auditório da UC.

1 MARÇO 2013 | Conferência de Jorge Custódio

Etapas da história do património em Portugal.

| Conferência de Ana Paula Amendoeira

"Do património ao património mundial: um percurso geopolítico para um conceito de dominação".

8-9 MARÇO 2013 | $1^{\circ}$ Encontro de doutorandos do $3^{\circ}$ Ciclo em Altos Estudos em História da FLUC. 
9 MARÇO; 19 ABRIL; 4 MAIO 2013 | Conferências Internacionais de História 2013

\section{Conferencistas:}

Faramerz Dabhoiwala, "The first sexual revolution".

Bernardo de Vasconcelos e Sousa, "Ceuta e as origens da expansão portuguesa”.

Dulce Freire, “"Mais fome do que fartura”. Propaganda e consumos alimentares durante o Estado Novo".

24 ABRIL 2013 | Conferência de João Vieira Caldas e Maria Helena Barreiros

"A exceção e a regra. Habitação nobre e corrente em Lisboa, da Restauração às Invasões Francesas”.

16, 24, 30 MAIO 2013 | Workshops de Modelação, Cozedura e Quebra

Tu fazes, eu parto, juntos colamos. Contributos da etnografia e arqueologia experimental na interpretação de cerâmicas. You make, I break, we glue. Ethnography and experimental insights on pottery interpretation, no Palácio de SubRipas.

\section{9-11 MAIO 2013 | III Encontro Anual da AIM}

Associação de Investigadores da Imagem em Movimento.

22 MAIO 2013 | Conferência de Juan Manuel Santana Pérez "Amor e sexualidade no Antigo Regime".

23 MAIO 2013 | Conferência de Juan Manuel Santana Pérez Os outros, a condenação histórica do racismo no mundo ocidental.

24 MAIO 2013 | Seminário aberto de Sara Bravo Ceia 
Os clérigos regulares de São Caetano em Portugal (Séculos XVII e XVIII): espaços, práticas e objetos de saber - Elementos de uma investigação em curso.

29 MAIO 2013 | Mestrado em História. Workshop. Dissertações 2012-2013

Moderadora: Ediana Ferreira Mendes.

Participantes:

Jorge Parta, “D. Afonso IV: Normatividade e poder."

Roger Lee, "O segundo cerco de Diu (1546): entre o mito e a realidade".

Cristóvão Mata, "A investigação em história do poder local: Penela entre a Restauração e o Liberalismo”.

Tiago Gomes, "Os acontecimentos de Rio Maior e a dicotomia Norte-Sul entre 1974 e 1976".

29 MAIO 2013 | Aula aberta de Walter Rossa

“De Chaul a Damão: Um território na Ásia, processos coevos e heranças atuais".

\section{Departamento de Línguas, Literaturas e Culturas}

10 OUTUBRO 2012 | Aula pelo docente convidado Lieuwe Noordam (docente do conservatório de Groningen e Instituto Superior de Zwolle): aprender neerlandês a cantar.

22 OUTUBRO 2012 | Inauguração do Centro de Estudos Russos.

7 DEZEMBRO 2012 | Colóquio «Jean-Jacques Rousseau em Debate:

Sociedade, Política e Estado - Trezentos anos Depois» organizado pelo Departamento de História, Arqueologia e Artes / Centro 
de História da Sociedade e da Cultura; Departamento de Filosofia, Comunicação e Informação / Unidade de Investigação "Linguagem, Interpretação e Filosofia»; e Departamento de Línguas, Literaturas e Culturas / Centro de Literatura Portuguesa.

12 DEZEMBRO 2012 | Apresentação sobre o escritor neerlandês J. Slauerhoff e a relação com Camões e Macau pelo docente convidado Arie Pos (tradutor literário e vice presidente da Associação Het Komrijk). Apresentou também a sua tradução para o Neerlandês de Os Lusíadas de Luís de Camões.

13 DEZEMBRO 2012 | "United Colors of Benetton:

Cultura italiana, cultura globale" pelo Dr. Alessandro Tucci, Diretor Geral da Benetton Portugal.

12 FEVEREIRO 2013 | Palestra temática:

70. ${ }^{\circ}$ Aniversário da Vitória na Batalha de Estalinegrado e o seu valor durante a Segunda Guerra Mundial.

5 MARÇO 2013| No âmbito da XV Semana Cultural da UC:

Colóquio sob o tema Língua Líquida, no período de 5 a 14 de março de 2013;

Terceira edição do Ciclo de Cinema 'Babel', nos dias 4, 5 e 7 de março de 2013, no qual foram apresentadas três produções cinematográficas de língua espanhola, italiana e alemã.

Apresentação de trabalhos de estudantes na área da poesia russa (traduções e declamações). Estes trabalhos foram, posteriormente, filmados nos estúdios da UCV e publicados no site da UC.

11 MARÇO 2013| Colaboração com o projeto Língua Líquida no âmbito da XV Semana Cultural da UC. 
14 MARÇO 2013 | Palestra dedicada à celebração da Maslenitsa. Visualização do filme "Maslenitsa» do Centro de Arte Popular Russa LADA.

2 a 5 ABRIL 2013| Coorganização da $6{ }^{a}$ edição de

"8 1 1 2 Festa do Cinema Italiano", em Coimbra, no Teatro Académico Gil Vicente.

Do Programa constava a exibição de:

Em sessão competitiva:

A.C.A.B All cops are bastards, de Stefano Sollima;

Bellas mariposas, de Salvatore Mereu;

Gli equilibristi, de Ivano De Matteo;

I primi della lista, de Roan Johnson;

Il Futuro, de Alicia Scherson;

Io sono $L i$, de Andrea Segre;

Pulce non c'è, de Giuseppe Bonito.

Panorama:

Romanzo di una Strage, de Marco Tullio Giordana;

La miglior offerta, de Giuseppe Tornatore;

È stato il figlio, de Daniele Cipri;

Una Famiglia Perfetta, de Paolo Genovese;

L'intervallo, de Leonardo Di Costanzo.

Outras projeções:

La leggenda di Kaspar Hauser, de Davide Manuli;

Su Re, de Giovanni Colombu;

Tulpa, de Federico Zampaglione; 
Tutto parla di te, de Alina Marazzi.

"Focus: Mani in alto!":

Milano Calibro 9, de Fernando Di Leo;

La mala ordina, de Fernando Di Leo;

Il boss, de Fernando Di Leo;

Milano odia: la polizia non può sparare, de Umberto Lenzi;

Vamos a matar, compañeros!, de Sergio Corbucci;

Keoma, de Enzo G. Castellari;

Se sei vivo spara, de Giulio Questi;

Da uomo a uomo, de Giulio Petroni;

Eurocrime!, de Mike Malloy.

Amarcord:

La guerra dei vulcani, de Francesco Patierno;

$81 / 2$, de Federico Fellini;

Il Gatto Pardo, de Luchino Visconti.

Curtas metragens:

Cusutu'n coddu (Cucito addosso), de Giovanni La Parola;

Dell'ammazzare il maiale, de Simone Massi;

La colpa, de Francesco Prisco;

Terra, de Piero Messina;

Training autogeno, de Astutillo Smeriglia.

Sessão especial de curtas metragens:

Appunti per un film su Rodolfo Valentino Alessio di Zio: La famiglia dell'orco; 
Le favole di Casimiro.

Ascolta:

Calibro 35.

Sessões especiais:

Benfica-Torino 4-3, de Andrea Ragusa e Nuno Figueiredo;

Cine-Jantar: Miseria e nobiltà, de Mario Mattoli;

Morte em Veneza, de Luchino Visconti. 
EVENTOS DE NATUREZA PEDAGÓGICA

\section{Departamento de Filosofia, Comunicação e Informação}

8 a 12 ABRIL 2013 | II Semana do Jornalismo

\section{Departamento de História, Estudos Europeus, Arqueologia e Artes}

10 DEZEMBRO 2012 | Visita de estudo ao Arquivo Nacional da Torre do Tombo

Mestrado em História - Idade Média

29 OUTUBRO 2012 | Visita de estudo à Catedral de Braga e Arquivo Distrital da Sé

Mestrado e Licenciatura em História

(Organizada pelas Doutoras Maria Helena Coelho e Teresa Veloso)

12 NOVEMBRO 2012 | Visita de estudo à Biblioteca Pública do Porto e ao Arquivo Histórico do Porto

Mestrado e Licenciatura em História

(Organizada pelas Doutoras Maria Helena Coelho e Teresa Veloso)

26, 27 ABRIL 2013 | Visita de estudo a Guimarães, Braga, Dume, Póvoa de Lanhoso e S. Miguel de Seide (Organizada pelo Doutor João Gouveia Monteiro) 


\section{Departamento Línguas, Literaturas e Culturas}

15 MARÇO 2013 | Encontro com alunos do Ensino Básico

Palestra «Os Mais Importantes Acontecimentos na História e na Vida Contemporânea da Rússia».

30 ABRIL 2013 | Festividades: entronização do novo rei dos Países Baixos.

Realização de uma palestra temática, dedicada à Celebração da Páscoa na Rússia, resumindo a essência de algumas tradições da Ortodoxia: a Semana de Queijo (Grande Maslenitsa), o Domingo de Perdão (antes da Quaresma) e a Grande Quaresma. A palestra foi acompanhada da visualização do filme Páscoa. Costumes Pascoais, da série "A Lei de Deus".

3 MAIO 2013 | Aula "A Temática da Grande Guerra Patriótica na Literatura Russa", por ocasião do $68^{\circ}$ Aniversário da Vitória do povo soviético na Grande Guerra Patriótica (1941-1945). Na palestra participaram os estudantes da unidade curricular de «Introdução à Literatura Russa", fazendo um breve resumo de algumas obras literárias sobre este tema.

24 MAIO 2013 | Aula aberta, dedicada ao Dia da Escrita e Cultura Eslavas (1150 anos), ao Dia Internacional da Língua Russa e ao $1025^{\circ}$ Aniversário da Aceitação do Cristianismo pela Rússia com a participação dos tradutores portugueses de literatura russa Nina Okuneva-Guerra e Filipe Guerra, sobre os temas: "A Importância da Escrita Eslava na Criação da Civilização Ortodoxa Russa» e "Clássicos da Literatura Russa na Língua Portuguesa».

JUNHO 2013 | Preparação de estudantes das unidades curriculares de Língua e Cultura Russas e Russo do Quotidiano para um 
estágio na Escola de Verão do Instituto Estatal de Língua Russa de A.S. Púchkin.

12 JUNHO 2013 | Encontro com os leitores da B.M.C.

Dedicado ao Dia da Rússia, sobre o tema: "Língua e Literatura Russas em Portugal e no Mundo». 
(Página deixada propositadamente em branco) 


\section{P U B L I C A Ç Õ E S}

\section{Departamento de Filosofia, Comunicação e Informação}

5 JUNHO 2013 | Lançamento do livro Justiça e Comunicação: o diálogo (im)possível, coordenado por Rita Basílio de Simões, Carlos Camponez e Ana Teresa Peixinho, com chancela da IUC.

Departamento de História, Estudos Europeus, Arqueologia e Artes

13 DEZEMBRo 2012 | Apresentação do vol. 43 da Revista Portuguesa de História

(Por Clara Almeida Santos, na Casa das Caldeiras)

5 MARÇO 2013 | Apresentação do vol. 33 da Revista de História das Ideias - O Corpo

$\mathrm{Na}$ ocasião, Maria Rita Lino Garnel fez a conferência "Epistemologia médica do corpo", na FLUC.

\section{Departamento de Geografia}

Publicação do número duplo de Cadernos de Geografia (30/31), de 2011/12; bem como do n. ${ }^{\circ} 32$ de 2013. Estes dois últimos volumes resultaram, sobretudo, da publicação de comunicações apresentadas ao VII Colóquio de Geografia de Coimbra. 
(Página deixada propositadamente em branco) 


\section{PUBLICAÇÕ ES RECEBIDAS POR OFERTA OU P E R M U T A}

\section{Livros}

A.A. (2008) - CONTRIBUTOS para a história medieval de Sintra. Atas do I Curso de Sintra. Sintra : Câmara Municipal de Sintra, 2008.

MAGALHÃES, A. (2013) - vol. 8 de Estudante faz arte: É Fenomilho - Fundação da Casa da Cultura do Milho.

MARQUES, R. R. (2013) - Poesia reunida. Unipam. Minas Gerais: Fundação Educacional de Pato de Minas. Univ. Minas Gerais.

ÁLVAREZ BARREDO, M. (2012) - El libro de Malaquías: dependência terminológica y fines teológicos. Múrcia : Instituto Teológico de Múrcia, Editorial Espigas (PITM Serie Mayor; 57).

MONTERROSO, G. (2012) - Prespectivas y desafios de la universidad: el compromiso social y ético y sus dimensiones internacional y regional Congreso Intercional de Educación Superior. Buenos Aires : Universidad del Salvador.

\section{Revistas}

Aevum. Rassegna di Scienze Storiche Linguistiche e Filologiche, LXXXVI, 2 (Università Cattolica del Sacro Cuore, Milano, Settembre-Dicembre, 2012). ISSN 0001-9593 Aevum. Rassegna di Scienze Storiche Linguistiche e Filologiche, LXXXVI, 2 (Università Cattolica del Sacro Cuore, Milano, Gennaio-Aprile, 2013). ISSN 0001-9593

Aevum. Rassegna di Scienze Storiche Linguistiche e Filologiche, LXXXVI, 3 (Università Cattolica del Sacro Cuore, Milano, Maggio-Agosto, 2013). ISSN 0001-9593

Anuario de Estudios Americanos, 69/2 (Escuela de Estudios Hispano-Americanos, jul.-dic., 2012). ISSN 0210-5810.

Anuario de Estudios Americanos, 70/1 (Escuela de Estudios Hispano-Americanos, ene.-jun., 2013). ISSN 0210-5810.

Anuarul Institutului de Etnografie și Folclor "Constantin Brăiloiu", nova série, tomo 22 (Academia Română, 2011). 
Archivo Teológico Granadino, 75 (Facultad de Teología, Granada, 2012).ISSN 0210-1629 Archivum Historicum Societatis Iesu, LXXX, 160 (July-December, 2011/I).

Archivum Historicum Societatis Iesu, LXXX, 160 (July-December, 2011/II).

Archivum Historicum Societatis Iesu, LXXXI, 161/I, 2012.

Archivum Historicum Societatis Iesu, LXXXI, 162/II, 2012.

Avgvstinvs, LVII, 226-227 (Madrid, Julio-Diciembre, 2012).

Avgvstinvs, LVIII, 228-229 (Madrid, Enero-Junio, 2013).

Avgvstinvs, LVIII, 228-229 (Madrid, Julio-Diciembre, 2013).

Beira Alta, LXVIII e LXIX, $1 .^{\circ}$ e $2 .^{\circ}$ semestre (Assembleia Distrital de Viseu, 2009).

Beira Alta, LXX, $1 .^{\circ}$ e $2 .^{\circ}$ semestre (Assembleia Distrital de Viseu, 2010).

Beira Alta, LXXI, $1 .^{\circ}$ e $2 .^{\circ}$ semestre (Assembleia Distrital de Viseu, 2011).

Boletim da Faculdade de Direito, LXXXVIII (Tomo I), (Univ. de Coimbra, 2012).

Boletim da Faculdade de Direito, LXXXIX (?) (Tomo I), (Univ. de Coimbra, 2013).

Boletim da Sociedade de Geografia de Lisboa, Série 129, 1-12 (Fundação para a Ciência e Tecnologia, janeiro-dezembro, 2011).

Brotéria. Cristianismo e Cultura, 177, 4 (outubro, 2013). ISSN 0870-7618.

Brotéria. Cristianismo e Cultura, 177, 5 (outubro, 2013).

Brotéria. Cristianismo e Cultura, 177, 6 (dezembro, 2013).

Cadernos de História e Memória Local, vol. I, 2012, Câmara Municipal de Santo Tirso, ISSN 978-972-8180-30-0

Carthaginensia. Revista de Estudios e Investigación, XXVII, 52 (Universidad de Murcia Julio-Diciembre, 2011).

Carthaginensia. Revista de Estudios e Investigación, XXVIII, 53 (Universidad de Murcia Enero-Junio, 2012). ISSN 0213-4381.

Carthaginensia. Revista de Estudios e Investigación, XXVIII, 54 (Universidad de Murcia Julio-Diciembre, 2012). ISSN 0213-4381.

Carthaginensia. Revista de Estudios e Investigación, XXIX, 55 (Universidad de Murcia Enero-Junio, 2013). ISSN 0213-4381.

Comunicações Geológicas, 95 (INETI, Lisboa, 2008).

Comunicações Geológicas, 96 (INETI, Lisboa, 2009).

Comunicações Geológicas, 97 (INETI, Lisboa, 2011).

Cuadernos de Aragón, 46 (Institución "Fernando el Católico" Zaragoza, 2011).

Cuadernos de Aragón, 48 (Institución "Fernando el Católico" Zaragoza, 2011).

Cuadernos de Aragón, 51 (Institución "Fernando el Católico" Zaragoza, 2011).

Cuadernos de Aragón, 52 (Institución "Fernando el Católico" Zaragoza, 2012).

Cuadernos de Investigación Filológica, tomo XXXV-XXXVI (Universidad de la Rioja, Logroño, 2009-2010).

Cuadernos de Investigación Filológica, tomo XXXVII-XXXVIII (Universidad de la Rioja, Logroño, 2011-2012). 
Cultura. Revista de História e Teoria das Ideias Vol. 28/2011, (II série) - Centro de História da Cultura (FCSH) da Univ. Nova de Lisboa, ISSN: 0870-4546.

Cultura. Revista de História e Teoria das Ideias Vols. 29/30 2012, (II série) - Centro de História da Cultura (FCSH) da Univ. Nova de Lisboa, ISSN: 0870-4546.

Diacrítica. Série Ciências da Literatura, 25/3 (Centro de Estudos Humanísticos da Universidade do Minho, 2010).

Diacrítica. Série Ciências da Literatura, 25/3 (Centro de Estudos Humanísticos da Universidade do Minho, 2011).

Diacrítica. Série Ciências da Literatura, 26/3 (Centro de Estudos Humanísticos da Universidade do Minho, 2012).

Didaskalia, XLII, 2 (Faculdade de Teologia de Lisboa, 2012). ISSN 0253-1674.

Epos. Revista de Filología, XXVII (Universidad Nacional de Educación a Distancia, Facultad de Filología, Madrid, 2011).

Epos. Revista de Filología, XXVIII (Universidad Nacional de Educación a Distancia, Facultad de Filología, Madrid, 2012).

Escola Moderna. Revista do Movimento da Escola Moderna, 44, 5. ${ }^{a}$ série (Movimento da Escola Moderna, Lisboa, 2012).

Estudios Mindonienses, 28 (Centro de Estudios de la Diócesis de Montoñedo-Ferrol, 2012). ISSN 0213-4357

Forma breve, 8 (Universidade de Aveiro, Departamento de Línguas e Culturas, 2010). ISSN 1645-927X

Franciscanum. Revista de las Ciencias del Espirito, vol. LIII, 155 (Universidad de San Buenaventura, Facultad de Filosofía y Facultad Teología, Bogotá, Ene.-Jun., 2011).

Franciscanum. Revista de las Ciencias del Espírito, vol. LIII, 156 (Universidad de San Buenaventura, Facultad de Filosofía y Facultad Teología, Bogotá, Jul.-Dic., 2011).

Horizontes, Revista de la Universidad Católica de Puerto Rico, (Año LIV, n ${ }^{\circ}$ s 104-105, primavera/otoño 2011). ISSN - 0018-5027

Humanística e Teologia, XXXIII, 1 (Faculdade de Teologia, Porto, junho, 2012).

Humanística e Teologia, XXXIII, 2 (Faculdade de Teologia, Porto, dezembro, 2012). ISSN - 080X

Humanística e Teologia, XXXIV, 1 (Faculdade de Teologia, Porto, junho, 2013). ISSN $-080 \mathrm{X}$

Humanitas, LXIII (Instituto de Estudos Clássicos da FLUC, Coimbra, 2012).

Igreja e Missão, 222, Ano 66 (janeiro-abril, 2013). ISSN 0251-3595

Igreja e Missão, 223, Ano 66 (maio-agosto, 2013). ISSN 0251-3595

Igreja e Missão, 224, Ano 66 (setembro-dezembro, 2013). ISSN 0251-3595

Itinerarium. Revista Quadrimestral de Cultura, LVIII, 204 (setembro-dezembro, 2012). ISSN 0021-3209

Itinerarium. Revista Quadrimestral de Cultura, LIX, 205 (janeiro-abril, 2013). ISSN 0021-3209 
Itinerarium. Revista Quadrimestral de Cultura, LIX, 206 (maio - agosto, 2013). ISSN 0021-3209

Jerónimo Zurita. Revista de História, 86, 2011 (Instituición "Fernando el Católico", Zaragoza, 2011).

Jerónimo Zurita. Revista de História, 87, 2012 (Instituición "Fernando el Católico", Zaragoza, 2012). ISSN 0044-5517

Laval Théologique et Philosophique, 68, 3 (Québec, Octobre, 2012). ISSN 0023-9054

Laval Théologique et Philosophique, 69, 1 (Québec, Février, 2013). ISSN 0023-9054

Laval Théologique et Philosophique, 69, 2 (Québec, Juin, 2013). ISSN 0023-9054

Línguística. Revista de Estudos Linguísticos da Universidade do Porto, vol. 5, 1 (Universidade do Porto, 2010).

Lusitania Sacra. Revista do Centro de Estudos de História Religiosa, 2. ${ }^{a}$ Série, Tomo XXVI (Universidade Católica Portuguesa, Lisboa, julho-dezembro, 2012). ISSN 978-972-8361-48-8

Lusitania Sacra. Revista do Centro de Estudos de História Religiosa, 2. ${ }^{a}$ Série, Tomo XXVII (Universidade Católica Portuguesa, Lisboa, janeiro-junho, 2013). ISSN 978-972-8361-48-8

Máthesis, 21 (Universidade Católica Portuguesa. Departamento de Letras, 2012). ISSN 0872-0215

Máthesis, 21 (Universidade Católica Portuguesa. Departamento de Letras, 2013). ISSN 0872-0215

Miscelánea Comillas. Revista de Ciencias Humanas y Sociales, 69, 135 (Universidad Pontifícia Comillas, Madrid, Julio-Diciembre, 2011). ISSN 0210-9522

Miscelánea Comillas. Revista de Ciencias Humanas y Sociales, 70, 136 (Universidad Pontifícia Comillas, Madrid, Enero-Junio, 2012). ISSN 0210-9522

Miscelánea Comillas. Revista de Ciencias Humanas y Sociales, 70, 137 (Universidad Pontifícia Comillas, Madrid, Julio-Diciembre, 2012). ISSN 0210-9522

Nueva Revista de Filología Hispánica, LIX, 1 (El Colegio de México, 2011). ISSN 0185-0121

Nueva Revista de Filología Hispánica, LIX, 2 (El Colegio de México, 2011). ISSN 0185-0121

Nueva Revista de Filología Hispánica, LX, 1 (El Colegio de México, 2012). ISSN 0185-0121

Nueva Revista de Filología Hispánica, LX, 2 (El Colegio de México, Julio-Diciembre, 2012). ISSN 0185-0121

Outra travessia. Florianópolis, 13, $1^{\circ}$ semestre, 2012 Revista de literatura, Univ. Federal de Santa Catarina Brasil.

Outra travessia. Florianópolis, 14, $2^{\circ}$ semestre, 2012 Revista de literatura, Univ. Federal de Santa Catarina Brasil. ISSN 2176-8552

Remate de Males. Revista de Teoria e História Literária, 30.1 (Universidade Estadual de Campinas, Instituto de Estudos da Linguagem, Campinas) janeiro/junho, 2010). ISSN 0103-183X

Remate de Males. Revista de Teoria e História Literária, 30.2 (Universidade Estadual de Campinas, Instituto de Estudos da Linguagem, Campinas) janeiro/junho, 2010). ISSN 0103-183X 
Remate de Males. Revista de Teoria e História Literária, 31.1-2 (Universidade Estadual de Campinas, Instituto de Estudos da Linguagem, Campinas janeiro/dezembro, 2011). ISSN 0103-183X

Remate de Males. Revista de Teoria e História Literária, 32.1 (Universidade Estadual de Campinas, Instituto de Estudos da Linguagem, Campinas janeiro/junho, 2012). ISSN 0103-183X

Revista Agustiniana, LIII, 160 (Publicación de pensamiento religioso de los Augustinos de Castilha, Madrid, Enero-Abril, 2012).

Revista Agustiniana, LIII, 162 (Publicación de pensamiento religioso de los Augustinos de Castilha, Madrid, Septiembre-Diciembre, 2012). ISSN 0211-612X

Revista Agustiniana, LIV, 163 (Publicación de pensamiento religioso de los Augustinos de Castilha, Madrid, Enero-Abril, 2013). ISSN 0211-612X

Revista ALPHA. Ano 13, 13 (Centro Universitário de Patos de Minas, novembro, 2012). ISSN 1518-6792

Revista de Estudios Extremeños, LXVIII, III (Centro de Estudios Extremeños, Badajoz, Septiembre-Diciembre, 2012). ISSN 0210-2854

Revista de Estudios Extremeños, LXIX, I (Centro de Estudios Extremeños, Badajoz, Enero - Abril, 2013). ISSN 0210-2854

Revista de Estudios Extremeños, LXIX, III (Centro de Estudios Extremeños, Badajoz, Septiembre-Diciembre, 2013). ISSN 0210-2854

Revista de Etnografie și Folclor, nova série, 1-2 (Academia Română, 2011).

Revista de Etnografie și Folclor, nova série, 1-2 (Academia Română, 2012).

Revista de Filologia, 30 (Universidad de la Laguna, 2012). ISSN 0212-4130.

Revista de Filologia, 31 (Universidad de la Laguna, 2013). ISSN 0212-4130.

Revista de Filologia y Lingüística de la Universidad de Costa Rica, 36, 2 (Universidad de Costa Rica, Julio-Diciembre, 2010).

Revista de Filologia y Lingüística de la Universidad de Costa Rica, 37, 2 (Universidad de Costa Rica, Julio-Diciembre, 2011). ISSN 0377-628X

Revista Galega de Filoloxía, 13(Universidad de la Coruña), 2012. ISSN 1576-2661.

Revista de Filsofía de la Universidad de Costa Rica, 126, vol. XLIX (San José, Costa Rica, Enero-Abril, 2011).

Revista Militar, 65, 1 (Lisboa, janeiro, 2013).

Revista Militar, 65, 2 (Lisboa, fevereiro, 2013).

Revista Militar, 65, 3 (Lisboa, março, 2013).

Revista Militar, 65, 4 (Lisboa, abril, 2013).

Revista Militar, 65, 5 (Lisboa, maio, 2013).

Revista Militar, 65, 6/7 (Lisboa, junho/julho, 2013).

Revista Militar, 65, 8/9 (Lisboa, agosto/setembro, 2013).

Revista Militar, 66, 1 (Lisboa, janeiro, 2014).

Revista Militar, 66, 2/3 (Lisboa, fevereiro/março, 2014). 
Revista Militar, 66, 4 (Lisboa, abril, 2014).

Revista Militar, 66, 5 (Lisboa, maio, 2014).

Revista Portuguesa de História, 43 (Instituto de História Económica e Social da Universidade de Coimbra, 2012).

Revista Portuguesa de Humanidades. Estudos Linguísticos, 15, fasc. 1 (Univ. Católica Portuguesa, Fac. de Filosofia de Braga, 2011).

Revista Portuguesa de Humanidades. Estudos Literários, 15, fasc. 2 (Univ. Católica Portuguesa, Fac. de Filosofia de Braga, 2011).

Rivista di studi liguri, LXXIV (Istituto Internazionale di Studi Liguri, Museo Bicknell, Bordighera, Gennaio-Dicembre, 2008, 2011).

Rivista di studi liguri, LXXIV (Istituto Internazionale di Studi Liguri, Museo Bicknell, Bordighera, Gennaio-Dicembre, 2009 - 2010, 2012).

Signos Universitarios, XXXI, 48 (Universidad del Salvador, 2012). ISSN 0326-3932

Signos Universitarios, XXXII, 49 (Universidad del Salvador, 2013). ISSN 0326-3932

Studium Ovetense, XXXVIII (Instituto Superior de Estúdios Teológicos, Seminário Metropolitano de Oviedo, 2010).

Studium Ovetense, XXXVIII (Instituto Superior de Estúdios Teológicos, Seminário Metropolitano de Oviedo, 2010).

Studii și Comunicări de Etnologie. Nova série, tomo XXV (Institutul de Cercetări Sócio-Umane, Academia Română, 2011).

Teografias, 2 (Universidade de Aveiro, Dezembro de 2012).

Theologica, II série, XLVII, 2 (Universidade Católica Portuguesa, Faculdade de Teologia, Braga, 2012). 
(Página deixada propositadamente em branco) 


\section{Série Documentos}

Imprensa da Universidade de Coimbra

Coimbra University Press

2015

- U

C

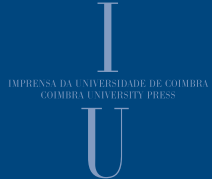

